\title{
El género de la intimidad: Katherine Mansfield y Clarice Lispector*
}

\author{
Alejandra Josiowicz ${ }^{* *}$
}

\begin{abstract}
Resumen
El artículo analiza problemas teóricos y críticos en relación a la escritura de la intimidad en los Diarios de Katherine Mansfield y en las crónicas del Jornal do Brasil de Clarice Lispector. En primer lugar, aborda la relación entre género literario y género sexual y entre feminismo y autobiografía. En segundo lugar, analiza la constitución de la voz en los géneros íntimos y problematiza la idea de intimidad tomando como punto de partida la teoría psicoanalítica. Luego, propone el análisis comparativo de ambas escritoras en torno a la idea de literatura periférica y a la de relación entre obra literaria e intimidad exhibida. Finalmente, se pregunta por el rol de la imagen de mujer y la comunidad femenina en su textualidad.
\end{abstract}

Palabras clave: Escritura Íntima, Género- Sexual, Subjetividad, Katherine Mansfield, Clarice Lispector.

\footnotetext{
* Recebido para publicação em agosto de 2008, aceito em novembro de 2009.

** Egresada de la Universidad de Buenos Aires, Argentina; cursa su doctorado en la Universidad de Princeton, Estados Unidos. ajosiowi@princeton.edu
}

cadernos pagu (34), janeiro-junho de 2010:301-329. 
El género de la intimidad

Writing, intimacy and gender: Katherine Mansfield \& Clarice Lispector

\begin{abstract}
The article deals with some of the theoretical problems of the writings of intimacy in the Journals of Katherine Mansfield and in chronicles written by Clarice Lispector in the Jornal do Brasil. Firstly, it examines the connections between literary genre and gender and between feminism and autobiography. Secondly, it considers the emergence of the self in the genres of intimacy and contends with the idea of the intimacy by making use of psychoanalytic theories. Subsequently, it analyzes both writers comparatively by considering the concept of the literature of the periphery. It also examines the bond between literary oeuvre and the intimacy exhibited in them. Finally, it judges the images of womanhood and of the feminine community in their intimate writings.
\end{abstract}

Key Words: Intimacy Writings, Gender, Subjectivity, Katherine Mansfield, Clarice Lispector. 
El siguiente artículo se propone explorar una serie de textos situados en la frontera entre el espacio íntimo y más personal de un escritor y el ámbito público de la escritura. Para pensar ese lugar de borde o grieta, desarrollaremos una serie de interrogantes productivos de acuerdo a una perspectiva crítico- literaria que intenta, por un lado, problematizar el concepto de sujeto autor como entidad homogénea y, por otro, pensar los dilemas que lo atraviesan en términos de género (-sexual). Surgirá, una y otra vez, la pregunta de bajo qué protocolos es posible leer textos en que lo más personal y biográfico se entrelaza fuertemente con la escritura pública y los protocolos de publicación. ¿Cómo articular obra y autobiografía cuando los paradigmas de la crítica se han liberado tanto del fantasma del análisis biográfico como del sujeto como negatividad? ¿Será posible problematizar tanto los procesos de constitución de la escritura como los de constitución del sujeto a la luz de una nueva conceptualización del yo literario? Se impone volver a rastrear las relaciones entre subjetividad y letra en términos que den cuenta del modo en que la vivencia del dolor se relaciona con la escritura. Asimismo, es necesario adoptar una mirada de género sobre la constitución del yo escriturario, toda vez que los haces identitarios de género (-sexual), de clase y de raza generan entonaciones específicas de la voz y tejen la trama de su acceso a la letra. La escritura como construcción de una voz narrativa -pública o íntima- requiere una reflexión sobre el género- sexual, al mismo tiempo que sobre el género- literario. En el caso de los textos que leeremos, ambos escritos por mujeres, en los que se viola sistemáticamente el espacio de lo íntimo a través de la cruda exposición de la subjetividad, la perspectiva de género resulta indispensable para entender qué tipo de transgresión intentan desplegar. Si rompen con la imagen de una femineidad sumisa al decir aquello que se suponía que una mujer no podía decir ni en el espacio privado ni en público, lo hacen quebrando las fronteras y el canon de los géneros y haciendo de la escritura su laboratorio de experimentación. 
El género de la intimidad

Los textos en los que analizaremos dicha unión máxima entre literatura e intimidad son el Diario (1987) de Katherine Mansfield y las crónicas reunidas bajo el título de Revelación de un mundo $(2004)^{1}$ escritas por Clarice Lispector para el Jornal do Brasil. Mansfield y Lispector trazan ante nuestros ojos el itinerario de una de las dilemáticas de la subjetividad del Siglo XX: ¿Cómo escribir "yo" justamente cuando la identidad ha estallado en mil pedazos? ¿Qué elecciones de técnicas y géneros de escritura se sobreimprimen con qué prácticas de constitución de sî́? Mientras la primera no escribe autobiografía sino diario, (diario de escritora frustrada, crónica de la agonía y la imposibilidad), la segunda expone su intimidad en pleno espacio público, exhibiéndose a sí misma como un ítem más en el mercado masivo de las comunicaciones. Pero la constatación de un quiebre en la subjetividad moderna no nos impide huir de cualquier diagnóstico apocalíptico; por el contrario, permite leer la escritura del yo como lugar de experimentación y puesta en juego de toda legitimidad. La hipótesis es que entre los diarios de Mansfield y las crónicas de Lispector se dibuja un arco que va de la escritura íntima como pathos del fracaso ("no puedo escribir", "no puedo ser quien soy") a la escritura cronística como performance triunfal del yo ante el receptor ("el sentido soy yo"). La escritora busca su remedio en la escritura, en la exhibición del dolor-de-ser fragmento, ser el nombre leído y el cuerpo de lo visto, la palabra pública. Y, por este mismo acto, corre el riesgo de inscribirse en la cultura, de alienarse, volverse hegemónica, marca petrificada que circula en innumerables intercambios simbólicos, sometida a infinidad de pequeños actos de significación. En la inscripción de la intimidad de ambas escritoras, leeremos la clave de la relación entre literatura y proyectos de liberación.

1 Coincido con su biógrafa, Nádia Battella Gotlib, quien afirma que dichas crónicas pueden considerarse "un extenso diario de Clarice Lispector" (Gotlib, 1995:376). 
Alejandra Josiowicz

\section{1) Género y escritura íntima}

Comenzaremos pensando el espacio de la escritura íntima como portador de una marca de género-sexual unida al género literario en el proceso de constitución de la subjetividad. La relación entre géneros menores (testimonios, diarios, cartas) con sujetos que carecen de acceso a las formas legitimadas de enunciación, como durante siglos lo han sido las mujeres, se vuelve entonces centro del debate. En primer lugar, es necesario reformular la tan mentada pregunta sobre si hay una escritura femenina diferente de la de los hombres en cuanto al género, al estilo o a la cualidad de la voz. Como la crítica feminista lo ha advertido, el problema debe plantearse en otros términos, evitando estigmatizar la escritura femenina, para así dar cuenta de cómo la práctica escrituraria de las mujeres ha debido refugiarse en los géneros que le eran permitidos - típicamente, aquellos relacionados con una idea de sentimentalidad $e$ intimidad femeninas - para acceder al lugar de enunciación. Como la crítica Sidonie Smith plantea, en tanto habitantes de los márgenes del discurso, las mujeres han quedado fuera de "géneros androcéntricos" y han sido encerradas en géneros menores como "cartas de amateur, diarios y anotaciones, escribiendo sus propias historias, pero de una forma más decorosa, al confinar su expresión al dominio doméstico" (1991:95). Según Smith, debido a esto, la autobiografía actual de mujeres se distingue justamente por ser portadora de la huella de la opresión y de la exclusión históricas. Se trataría de un "ventrilocuismo cultural" que dota a la autobiógrafa de una comprensión más profunda de su relación con el lenguaje patriarcal aprendido y con las narrativas de sí que otros le han enseñado a contar. Ahora bien, lo que Smith no considera es que a lo largo de todo el Siglo XX, las escritoras han luchado por incluirse en el canon y muchas lo han conseguido con éxito. Esto ha tenido consecuencias considerables, como son la estabilización y la legitimación de ciertos nombres de autoras asociados al prestigio de su obra. Es por eso que, en este ensayo, 
El género de la intimidad

intentaremos leer géneros todavía no enteramente legitimados por el canon literario, como son los diarios y las crónicas, para dar cuenta de los procesos por los cuales algunas escritoras, en lugar de luchar por las oportunidades que les ofrecían los géneros altos, eligieron transgredir no sólo una imagen impuesta de género sexual sino una jerarquía de géneros literarios.

Ahora bien, no nos adelantemos. La relación entre crítica feminista y autobiografía, o escritura del yo es profunda y tiene larga data. Como dice Ángel Loureiro en su Introducción a El gran desafío. Feminismos, autobiografía y posmodernidad (1994), el feminismo nace con la lucha de la mujer por decir "yo", por enunciar en primera persona y ser sujeto de su propia biografía, lo que desencadena una serie de dilemas de representación. Como más arriba hemos dicho, esta problematización se agudiza en los géneros íntimos, que funcionan como cárcel, el lugar de la "intimidad sensible" en donde las mujeres han sido encerradas históricamente por los estereotipos culturales. Sylvia Molloy advierte en "Identidades textuales femeninas: estrategias de autofiguración" (2006) que la mujer ha venido siendo objeto de representación literaria en América Latina, mucho más a menudo que sujeto de enunciación. Según Molloy, por su lugar exiliado de toda inscripción institucional, la autofiguración de la mujer pone en evidencia los resortes hegemónicos de toda representación, ya sea mediante el humor o la parodia de las propias mitologías construidas en torno a lo femenino.

Como parte del cada vez más complejo debate por la representatividad en los estudios feministas actuales, que incluye la pregunta por la politicidad de los géneros literarios y su uso por parte de hombres y mujeres, ha venido surgiendo un reclamo por "repersonalizar la identidad femenina" (Loureiro, 1994:28). Podemos pensar que la elección de géneros que habitan el espacio de lo íntimo, como los diarios o las cartas, contribuyen a poner en escena, con un énfasis específico, al yo. Estos géneros, además de ocupar un lugar periférico ante el canon, son particularmente propicios para el trabajo de autoconocimiento $y$ 
liberación del sujeto - mujer. Como dice Sidonie Smith (1994:39) en "El sujeto [femenino] en la escena crítica, la poética, la política y las prácticas autobiográficas", los géneros autobiográficos tienen una relevancia particular para todo grupo minorizado, como arma de defensa, testimonio histórico y lugar de expresión. El punto más interesante de la propuesta de Smith es su idea de pensar autobiográficamente, es decir, dotar de valor testimonial $\mathrm{y}$ psicobiográfico a textos quizás no canónicos y voces no occidentales que cuestionen las leyes de los géneros literarios y sus formas de organizar la subjetividad. Leer esos textos de mujeres como documentos de marginalidad histórica y resistencia potencial permite alumbrar herramientas discursivas que trazan vías no hegemónicas de constitución de sí.

La tarea que se le impone a una crítica de género en la actualidad es entonces la de descentrar el sujeto universal, el hombre blanco heterosexual y su correlato femenino neutralizado, $\mathrm{y}$, de este modo, dejar espacio a la voz de las minorías (raciales, coloniales, de clase) que se superponen a la identidad femenina oprimida. Tanto en el caso de Katherine Mansfield como en el de Clarice Lispector, como sujetos cuyo acceso a la esfera pública y a la vida literaria fue problemático, podemos advertir un doble movimiento: por un lado, un intento de legitimar su propia voz enmascarándose con los estereotipos de lo femenino y con las marcas de legitimación de la cultura nacional en la que pretendían insertarse (la inglesa para una inmigrante de la colonia de Nueva Zelanda, la brasileña para una inmigrante ucraniana judía que creció escuchando el yiddish (Pazos Alonso y Williams, 2002:22). Pero, superpuesto a ese intento, también es posible observar un proyecto de liberación de la voz, que no se restringe al ámbito personal. En la vida y en la obra de ambas escritoras se advierten rastros de rebeldía frente a los roles asignados a la mujer $y$, sobre todo, un proyecto claro de construcción de un grupo de pertenencia, de mutua solidaridad, con otras mujeres. La necesidad de rodearse de interlocutoras femeninas, que enmarquen la práctica literaria de estas escritoras en dispositivos 
El género de la intimidad

no jerárquicos de intercambio, se vuelve entonces patente en los dos casos.

Katherine Mansfield no sólo se dedicó a realizar reseñas de escritoras para las revistas en la que contribuyó - como Athenaeum -, lo que delata un interés específico por la escritura de mujeres, sino que estableció una excepcional relación de cooperación intelectual - que no excluyó la competencia - con Virginia Woolf. Su dificultad por vivir de acuerdo a los parámetros de una sociedad patriarcal - su vida estuvo marcada por embarazos, abortos esporádicos, sexualidad no disciplinada, moral extravagante, repetidos fracasos matrimoniales, ${ }^{2}-$ se traduce en una tendencia a la bisexualidad - que aparece como tópico en su literatura, junto al tema del amor lésbico, que surge en su diario y en algunos de sus cuentos (Nathan, 1993:6). Por otro lado, a medida que su enfermedad avanzaba, se hizo presente en ella una necesidad de establecer lazos cada vez más íntimos con mujeres, lo que se advierte tanto en sus diarios como en las cartas. Sin embargo, es necesario advertir que no hay en Mansfield un reclamo por una escritura feminista sino un rechazo de la idea de "prosa femenina" 3 - lo que puede atribuirse a su sensibilidad modernista y a su interés por la experimentación formal con la voz. De cualquier modo, en la idea del escritor como voz andrógina (1994:109) y en la relatividad de los constructos de género - masculino o femenino -, que Mansfield nunca ve como fijos (1994:110), podemos advertir la emergencia de una especie de literatura bisexual, que advierte sobre la naturaleza huidiza y ambivalente de la identidad sexual humana.

Por otro lado, como proveniente de una cultura colonizada como es la neozelandesa ante la metrópolis británica, la literatura

2 "El matrimonio será sinónimo de ansiedad para ella, no de felicidad amorosa", como dice Rhoda B. Nathan en su artículo "The life as a source" (Nathan, 1993:8).

3 Elaine Showalter ofrece una clave para entender este rechazo de Mansfield en la "naturaleza puntitiva de su ficción" (citado en Hanson, Clare. "Introduction to the Critical writings of Katherine Mansfield" (Nathan, 1994:224). 
de Mansfield problematiza implícitamente cuestiones de género uniéndolas indisolublemente con cuestiones de raza. En sus textos la idea de la homosexualidad femenina aparece frecuentemente ligada a mujeres Maoríes, con lo cual la imagen de la diferencia étnica abre la posibilidad de un tipo de subjetividad sexual distinta. Los estereotipos de la identidad colonial aparecen implícitamente parodiados en su literatura, junto al ridículo a que somete los roles de género. Debido a esto, los estudios críticos de la actualidad acerca de la literatura de Mansfield han rechazado la imagen de feminista simbolista y modernista europea, para restituir la carga política en su literatura, que la vuelve relevante para una lectura poscolonial y minoritaria (ver Bridget Orr, 1993:58).

Clarice Lispector también intentó establecer una serie de relaciones particularmente relevantes con otras mujeres. En primer lugar, reconoció a la propia Katherine Mansfield como una de las pocas figuras literarias de las que recibió influencia ${ }^{4}$. Por otro lado, sus empleadas domésticas fueron las únicas compañeras de su intimidad durante su vida adulta (ver Roncador, 2008), hasta tal punto que la figura de la "mucama" se volvió verdadero tópico en sus escritos. Además, el diálogo con las lectoras de las crónicas que escribe en distintas publicaciones de Brasil, algunas de ellas exclusivamente dedicadas al público femenino, surge como una instancia fundamental de formación de su literatura. Allí aparece tanto el ideal de mujer ama de casa y madre devota como la imagen de una mujer moderna que intenta emanciparse haciendo uso de todas las armas que le presta la civilización. En este sentido, la asociación cómplice con la lectora permite hacer de lo femenino algo escandalosamente público e íntimo al mismo tiempo, mientras que la feminización de la voz contribuye a parodiar todo estereotipo. Luiza Lobo, en su artículo "Feminism

${ }^{4}$ Según la autora admite, había leído el cuento "Bliss" a los quince años, y a partir de ese momento, leyó con avidez todo lo que encontró de esa escritora (Pazos and Williams, 2002:100). 
El género de la intimidad

or the ambiguities of the feminine in Clarice Lispector" (Pazos Alonso and Williams, 2002), analiza las crónicas que Lispector escribe en el Correio da Manhã bajo el pseudónimo de Helen Palmer, que incluyen consejos de belleza para mujeres. Y allí dice que en sus textos:

La belleza se muestra entonces como una liberación psicológica para las mujeres, de los problemas de la vida que no pueden ser fácilmente resueltos a largo plazo. Su identificación con lo "femenino" como intrínsecamente bello o elegante, característico de la esencia femenina, la ayudó a establecer un diálogo con sus lectoras mujeres. [Lispector] Se proyecta a sí misma como una mujer solitaria y victimizada, que recibe apoyo psicológico de una cadena de visitas femeninas, cartas y llamados telefónicos (2002:97, traducción y subrayado míos).

Paralelamente a Mansfield, Lispector sufre los prejuicios sociales respecto a su condición de mujer separada - el divorcio no se legaliza en Brasil hasta el año 1977, es decir, poco después de su fallecimiento - y termina sus días rodeada casi exclusivamente por una compañera femenina: Olga Borelli. Asimismo, al igual que Mansfield, Lispector no esgrime un feminismo explícito sino que contradice los presupuestos hegemónicos patriarcales en forma implícita, de modo doble: por un lado, transgrede el género crónica, volviéndolo escritura intimista que abre las puertas a la lectora femenina. Por otro, exhibe los estereotipos de lo femenino como máscara para esconder la ruptura que implica la liberación de los flujos del deseo en su literatura.

\section{2) Intimidad y extimidad. Subjetividad y géneros íntimos}

Con miras a una reflexión más profunda acerca del sujeto de los géneros íntimos, formularemos algunas aclaraciones acerca de su naturaleza. Para ello, utilizaremos una serie de conceptos 
psicoanalíticos, que resultan especialmente relevantes porque problematizan cualquier oposición binaria entre lo íntimo y lo externo al sujeto. ${ }^{5}$ Por otro lado, la idea de que el inconsciente es interior pero también intersubjetivo implica que el centro mismo del sujeto está fuera de él: el yo es, por excelencia, excéntrico. En El sublime objeto de la ideología, Slavoj Zizek (1989) plantea que lo más íntimo del sujeto es extra-subjetivo y que, como un tesoro escondido, se vuelve imposible de dominar o siquiera de nombrar. Todo proceso de subjetivación es entonces necesariamente un reconocimiento de culpa de quien se sabe impotente para responder al misterio. En este sentido es que el psicoanálisis piensa al sujeto como éxtimo ${ }^{6}$, situado en el borde entre exterioridad e interioridad y atravesado por ese vacío, la imposibilidad de responder (Zizek, 1989:178). Lo éxtimo, como intimidad externalizada, resulta un concepto especialmente útil porque nos recuerda la estrecha relación entre lenguaje $e$ inconsciente (Zizek, 1989:132), nos evita pensar la intimidad en términos de un "secreto" a revelar y nos ilumina su cualidad representacional. La escritura íntima, por lo tanto, ilustra la naturaleza anfibia de todo lenguaje, radicalmente interno, como

5 De hecho, el psicoanálisis no piensa en términos discretos los ejes oposicionales adentro- afuera, significante- significado, verdad- apariencia o continente y contenido sino como conceptos continuos (Evans, 1996).

6 Son varios los teóricos del psicoanálisis que piensan lo éxtimo. Jacques Lacan en el Seminario VII "La ética del psicoanálisis" (1992) plantea que el significante humano ya está instalado al nivel del inconsciente como alteridad radical. Lo más escondido, siendo centro de la subjetividad, dice Lacan, es también una representación. Lo éxtimo es la exterioridad más íntima o la intimidad más exterior. Asimismo, en el Seminario XI, "Los cuatro conceptos fundamentales del psicoanálisis" (1981), Lacan plantea que, dado que el inconsciente es el discurso del Otro, puede decirse que el sujeto contiene como lo más íntimo su extimidad. La extimidad implica que lo íntimo es el lenguaje del Otro. Por otro lado, Jaques Allain Miller dice que, además de permitir romper con la bipartición de la vida psíquica, el concepto de lo éxtimo indica que lo más íntimo tiene no sólo una cualidad de exterioridad sino también de opacidad, difuminando toda transparencia (1994:75). Se trata de un misterio, un cuerpo extraño o parásito que, una vez más, pone en evidencia al yo como alteridad (1994:80). 
forma material del inconsciente, y radicalmente externo, como murmullo de la alteridad más radical. En ella se advierte en qué sentido todo lenguaje desnuda lo más personal de un individuo $e$ ilumina, al mismo tiempo, aquello que lo excede.

Otro psicoanalista, Pierres Gilles Guéguen, en su ensayo "The intimate, the extimate and psychoanalyitic discourse" (2006), aborda la irrupción de la intimidad en la literatura, su valoración pública y estética. Según él, la emergencia de este fenómeno se relaciona históricamente con la confesión de lo indecoroso: un acto de verdad relacionado con la transgresión. La literatura íntima implicaría, según él, un uso de la verdad como confidencia en soledad que, sin embargo, no deja de pensar un otro- lectortestigo- cómplice (Guéguen, 2006:265). El sentimiento de intimidad genera un contagio histérico, dice Guéguen: el lector se identifica histéricamente con la verdad, dado que percibe lo íntimo como más verdadero que lo público y cotidiano. En este sentido, según Guéguen, los escritos íntimos pueden analizarse como éxtimos porque exhiben lo más oculto, exponen lo inconfrontable, lo más próximo al yo pero también más difícil de articular (Guéguen, 2006:269).

Por otro lado, teóricas feministas del psicoanálisis como Julia Kristeva se detienen a pensar la relación entre la letra y esa zona de indecibilidad en el caso particular de la mujer. Surge entonces la pregunta acerca de cuál es la relación entre experiencia traumática y letra publicable para las mujeres. ¿Cómo es que las escritoras transforman el dolor en escritura? ¿Qué género usan para hablar del trauma o del dolor? ¿La "tristeza femenina" es previa o surge del proceso mismo de alienación que, como hemos visto, atraviesa su acceso al lenguaje?

En Black sun. Depression and melancholia (1989), Kristeva analiza la escritura de la intimidad como escritura doliente (in-pain writing) y la relaciona estrechamente con el duelo por la pérdida del objeto materno como parte ineludible del proceso de individuación. En este sentido, para entender el rol fundamental del dolor (proveniente de una causa externa o inflingido a uno 
Alejandra Josiowicz

mismo) como motor de la escritura y fuente de placer en escritoras como Katherine Mansfield o Clarice Lispector, resultan indispensables las reflexiones de Kristeva en torno al narcisismo negativo en la mujer: "Modesta, silenciosa, ella dirige golpes morales y psíquicos contra sí misma, los cuales, sin embargo, nunca le reportan placer suficiente" (1989:30, traducción mía). Tal como Kristeva analiza en la poética de Marguerite Duras, para estas mujeres la literatura cumple no sólo un rol catártico sino de complicidad con la enfermedad ("La muerte y el dolor son las telas de araña que tejen el texto" [1989:229, traducción mía). La crisis psíquica o física genera en el lenguaje un estado experimental, y sus literaturas hacen de la enfermedad algo productivo. Histéricas o tuberculosas, pero nunca romanticonas sumisas, tanto Mansfield como Lispector hacen de la enfermedad y del dolor un modo de politizar la vida privada. En el caso de Mansfield, la tuberculosis, según críticas como Mary Burgan (1994), fue uno de los motores fundamentales de su escritura (de hecho, la sensibilidad sintomática y la estética del detalle marcaron su estilo). Mansfield supo apropiarse de las metáforas de la enfermedad y de la experiencia del dolor para dar intensidad a su escritura (1994:174). Lispector, por su lado, hace de la locura y del excentricismo psíquico un lugar de resistencia frente a los roles estereotipados de la mujer y del individuo en general. Lo cierto es que las dos supieron transformar el dolor privado en un asunto político ("Vivimos la realidad de un mundo sufriente" dice Kristeva [1989:235, traducción mía]). Como creadoras de una literatura íntima y enferma, ambas se comprometen en un duelo imposible por la identidad perdida. En el caso de la mujer, nos dice Kristeva, la tristeza por ese proceso no reprime sino que potencia los flujos de la escritura. Eso explica no sólo el torrente sino también el exhibicionismo exasperado que marca ambas estéticas. 
El género de la intimidad

\section{3) ¿Una literatura periférica?}

Katherine Mansfield nació en Nueva Zelanda en 1888 y murió en Francia en 1923 y Clarice Lispector nació en $1920^{7}$ en Ucrania y murió en 1977 en Brasil. La última fue lectora de la primera desde su juventud, y se reconoció plenamente en el proyecto escriturario de la otra. ${ }^{8}$ Las sometemos al ejercicio comparatista con la idea de que ambas son similares en su rebelión ante una idea estable o fija de literatura, sexualidad y nacionalidad. Son migrantes por razones meramente fácticas pero también por decisión propia, por una toma de partido a nivel político. ${ }^{9}$

Pero ¿por qué puede decirse que estas escritoras, hoy en día parte del canon literario, plantean la oportunidad de pensar una literatura periférica? Comenzaremos por analizar el caso de Katherine Mansfield. Es interesante considerar que Mansfield recibe su primera instrucción en una escuela de pueblo que, al decir de su viudo, no era diferente de la del "chico que traía la leche, y que las hijas de la lavandera". Más tarde viaja a concluirla en Inglaterra, madre patria que la deslumbra por su efervescencia cultural. Pero la semilla del malestar ya estaba sembrada. La marca de -lo que es percibido por ella como- educación frustrada y de su pertenencia a una cultura periférica la llevarían a elegir Inglaterra como lugar de residencia, con la idea de que allí iba a

7 O en 1925. Su biografía explica las contradicciones que hay entre sus documentos de nacimiento y entrada al Brasil en lo que respecta a su fecha de nacimiento (Gotlib, 1995).

8 "Emocionada, yo pensaba: ipero este libro soy yo! (...) Después me enteré de que la autora no era anónima, siendo, por el contrario, considerada uno de los mejores escritores de su época: Katherine Mansfield.", escribe Lispector en una de sus crónicas para el Jornal do Brasil (2004:323).

9 Con respecto a la política crítica de una literatura periférica, puede verse el ensayo de Gilles Deleuze y Felix Guattari “¿Qué es una literatura menor” (1978). 
poder satisfacer su voracidad intelectual. ${ }^{10}$ Sin embargo, nunca conseguiría establecerse en forma fija, dado que continuaría mudándose constantemente por Europa, viviendo en pensiones, inicialmente debido a un embarazo, más tarde por motivos económicos y por una afección pulmonar y cardiaca. Este nomadismo crónico de Mansfield se une a la paradoja de que en sus últimos años se lanza a una recuperación del pasado infantil y de la familia perdida, que se vuelve tema principal de sus relatos. Pero es en su diario en donde pone en juego una dinámica deseante que constantemente apunta hacia el hemisferio opuesto - la Nueva Zelanda que no volverá a ver jamás - y resta toda densidad a lo real.

Ya sabes que siempre me sentiré extranjera aquí (1987:63) [dice]

Inglaterra me es inútil. ¿Qué quiero decir con esto? Quiero decir que jamás ha existido ni existirá entre las dos ningún rapprochement. Jamás...Verdaderamente lo que detesto es la ausencia en ella de aquello que emociona (1987:142).

Nueva Zelanda es, por otro lado, el lugar donde se reinventa un público fantasmático: "todos tienen que tener este libro, todos los de allá" (1987:81). Si Europa es el lugar para vivir, la colonia, patria de la infancia, es el motor y la sustancia del escribir, con los ojos del que mira en el perpetuo exilio:

Quiero, por un instante, hacer surgir a los ojos del viejo mundo nuestro país inexplorado. Tiene que ser misterioso, casi como si flotara sobre las aguas, tiene que cortarle a uno la respiración. Tiene que ser "una de aquellas islas..." (1987:74, énfasis mío).

\footnotetext{
${ }^{10}$ Sigo aquí el testimonio de su esposo y editor póstumo John Middleton Murry en su "Introducción" al Diario (1987:12). Varios estudios críticos retoman esa tesis. Véase, por ejemplo, Gordon, 1954.
} 
El género de la intimidad

En los Diarios de Mansfield no hay estrictamente voluntad de literatura nacional porque no hay una sola nación en el horizonte: la palabra, y el misterio, nacen en la relación entre la literatura central (inglesa) y la periférica (neozelandesa), relación de desigualdad, de dependencia. El diario es el espacio donde irrumpe la colonia, en el que es posible construir una lengua literaria colonizada, fantasmática, evanescente. En este punto, cabe destacar que uno de sus críticos neozelandeses, Ian A. Gordon, ha llamado la atención acerca de la presencia de modismos y términos típicos del dialecto del inglés de Nueva Zelanda y de palabras de origen maorí en sus textos.

Por otro lado, en Mansfield siempre es la distancia, ya sea geográfica o la que imponen la literatura y la enfermedad, lo que pone en movimiento la escritura. En el último período de su vida, lleva esta tendencia al extremo hacinándose en un territorio expropiado de la realidad, habitado únicamente por ella y por el fantasma - las percepciones, sonidos e imágenes de su hermano muerto.

Clarice Lispector nació en Ucrania y vivió en Brasil, país al que llegó con dos meses de edad. Hija de inmigrantes judíos, debió mudar de residencia varias veces durante su vida, en primera instancia con su familia, debido a la pobreza del padre y a la muerte de la madre, y luego como esposa de un diplomático, lo que la llevó a residir tanto en Europa como en los Estados Unidos. Sin embargo, Lispector es lo opuesto a una internacionalista. No sólo porque se proclama brasileña y declara su deseo de pertenecer a la lengua portuguesa, sino, sobre todo, porque hay en ella una necesidad de anclaje. Con luminosa conciencia de que la pertenencia nacional genera marcas en la subjetividad, Clarice siente que ser brasileña implica una cualidad estético-política que la afilia a la periferia. Por otro lado, el público lector del Jornal do Brasil se obstina en verla como una extranjera; ante las cartas preguntando si es rusa, a causa de su apellido y su acento, Clarice responde defendiéndose como alguien a quien quisieran robarle la 
Alejandra Josiowicz

nacionalidad o exiliarlo de la pertenencia. ${ }^{11}$ Es justamente por ese riesgo latente que su brasileñismo se enuncia en términos de programa:

Si bien tengo una alegría: pertenezco, por ejemplo, a mi país, y como millones de otras personas soy pertenecida de él a tal punto, que soy brasileña. (...) No, no es por orgullo, ni por ambición. Estoy feliz de pertenecer a la literatura brasileña por motivos que nada tienen que ver con la literatura, pues ni siquiera soy una literata o una intelectual. Feliz sólo de "ser parte" (2004:91, los subrayados son míos).

A riesgo de incursionar en la psicobiografía, se podría pensar que en la base de esta necesidad de pertenecer, hay un dato biográfico: su orfandad, la muerte de la madre a la edad de diez años. Sin embargo, ante ese vacío fundante, en lugar de lanzarse a recuperar la lengua y la madre (patria), Lispector profundiza el estatuto carente, tanto de lengua ${ }^{12}$ como de patria, contra todo nacionalismo. Así, pone en evidencia cuánto de construido y artificial hay en toda nacionalidad.

\section{4) De "no encuentro el sentido" a "el sentido soy yo". El recorrido de la extimación}

Ahora bien, ¿Por qué relacionar estas dos formas, el Diario de K. Mansfield y las crónicas escritas durante siete años para el Jornal do Brasil? En primer lugar, debemos notar que en ambos

\footnotetext{
${ }^{11}$ Se trata de la crónica titulada "Aclaraciones- Explicaciones de una vez por todas" correspondiente al 14 de Noviembre de 1970 (2004:247-248).

${ }^{12}$ Con respecto al estatuto del portugués como lengua carente, Lispector dice: "Si (...) me preguntaran a qué lengua querría pertenecer, diría: al inglés, que es preciso y bello. Pero (...) se volvió absolutamente claro para mí que lo que yo quería realmente era escribir en portugués. Y hasta habría querido no haber aprendido otras lenguas: sólo para que mi abordaje del portugués fuera virgen y límpido" (79-80, subrayados míos).
} 
El género de la intimidad

casos la práctica de la escritura es sinónimo de vigilancia, exposición de sí y juicio. En Mansfield, la escritura del Diario es la crónica de la lucha y la capitulación de la escritora ante sí misma, ante un proyecto de escritura y subjetividad que constantemente se difiere - aún cuando más frecuentemente se inscribe -. En Lispector, por otro lado, el juez es el público del Jornal, ante el cual la escritora consagrada se desnuda una y otra vez en frenética danza. $\mathrm{Si}$, como ella dice, su proyecto es ganarse la vida mediante la escritura de esas crónicas, y su preocupación, conservar su intimidad resguardada del dominio público, ¿cómo podría pensarse fracaso peor que el de no poder escribir otra cosa que el sí mismo? En segundo lugar, en los dos se escenifica un dramático rechazo del yo, un martirologio y un sacrificio autoimpuesto que funda el sí mismo en las ruinas de toda identidad, que hemos visto como parte de la dinámica de deseo femenina. Mansfield lo hace en un ámbito simuladamente íntimo $y$ Lispector en uno descaradamente público. Mientras K. M. enuncia la idea de una práctica escrituraria transgresora de los "grandes géneros" y declara abiertamente su voluntad de publicar sus escritos íntimos $^{13}$, C. L. afirma reiteradamente su no-saber acerca de la escritura cronística y su prescindencia de toda distinción genérica, dado que toda escritura, para ella, es escritura de sí: "¿Ven ustedes qué a gusto estoy escribiendo? Sin mucho sentido, pero a gusto. ¿Qué importa el sentido? El sentido soy yo." (2004:160). Estos textos trazan el recorrido de una violenta extimación de la escritura del yo, latente en el primero, vuelta fenómeno performativo en el segundo. El yo se desbarranca y la escritura es no sólo testigo sino herramienta de la extimación de la intimidad.

13 "Y, por último, quiero anotar todo en un carnet pequeño, para que sea publicado algún día. Y nada más. Ni novelas, ni historias complicadas, nada que no sea sencillo, abierto" (1987:74-75, subrayado mío). Manifiesto de una obra sin género, sin trama ni personajes y sin ficción. Más adelante, sin embargo, contradice esta voluntad de publicación de su Diario: “....mi intención es que esto no lo lean ningunos ojos más que los míos. Estos apuntes son realmente privados. Y confieso que nada me proporciona mayor alivio" (1987:224). Esto último, escrupulosamente ignorado por J. M. Murry, editor y exégeta de su obra. 
Alejandra Josiowicz

\section{4.a) "Desde ahora, día por día tengo que llevar una cuenta exacta de mis fracasos"}

En la imposibilidad de escribir es donde reside toda la dinámica de la escritura mansfieldeana, así como la relación entre Obra y diario. Su obra literaria debe pensarse como un mero resto que ha escapado de esa lucha, una isla en el vacío. Como dice Roland Barthes (2003:20) respecto a la relación entre diario íntimo y obra en André Gide: la obra como creación de personajes y de un mundo ficcional traduce un deseo de ser alguien del escritor, de llenar el vacío en sí mismo y en el mundo. El diario íntimo de escritor, al ser la huella de esa imposibilidad, es escritura del sujeto-en-proceso, del sujeto-en-obra. En Mansfield, el Diario es el parte de la batalla espiritual de la escritora por acceder al lugar de enunciación, de productora de cultura:

Vuelvo a dormir mal y he decidido romper todo lo que he escrito y empezar de nuevo. Estoy segura de que esto es lo mejor. Esta miseria mía persiste y estoy completamente aplastada bajo su peso. Si algún día pudiera escribir con mi fluidez de antaño, el hechizo se rompería. Es el continuo esfuerzo, la lenta construcción de una idea, y luego delante de mis ojos, y fuera de mi poder su lenta disolución (1987:39).

Como crónica de un fracaso, el Diario es profundamente antiliterario, constituye una crónica del martirologio del yo, un forzamiento a ignorar el llamado de la vocación, del deseo humano y material de ser Autor. "No puedo escribir" se vuelve entonces no una imposibilidad sino una ascesis, una prohibición: "Mi deseo más profundo es el de ser un escritor, el de haber hecho "una obra". Y ahí está el trabajo, ahí me esperan las novelas, se cansan, se marchitan, se ajan, porque no quiero venir. Oigo, reconozco su presencia, y sin embargo sigo sentada en mi balcón, y juego con el ovillo de lana. ¿Qué es lo que hay que hacer?" (1987:237, énfasis míos). 
El género de la intimidad

Cuanto más frecuentemente escribe sus proyectos de obra en el diario, más definitivamente los difiere, autocastigo que, como vimos, es constitutivo de la jouissance femenina. Por otro lado, el "no puedo escribir" puede leerse también como un "no puedo ascender" de la voz femenina, "no puedo ser aquélla que estoy destinada a ser". Tiene horror a la improductividad y a la fragmentación - del cuerpo, de la letra y del yo -,

no quiero averiguar si esto es la verdadera tuberculosis: quizá se volverá galopante, ¿quién sabe? Y mi trabajo no estará terminado. Esto es lo que importa. Sería intolerable morir... dejar "fragmentos", "esbozos"... nada verdaderamente acabado (1987:105).

Como una coleccionista, había atesorado esos fragmentos en el reservorio de la escritura - el diario - pensando en su eventual utilidad. ${ }^{14}$ Toda la parafernalia autodisciplinaria que despliega el Diario está justamente destinada a surtir un efecto experimental sobre su vida y su obra: es invención de un orden autónomo, mucho más riguroso que cualquier norma social. En sus momentos de mayor lucidez, sin embargo, tiene conciencia de no ser completamente íntima, de que algo terminaba por "emerger" de su escritura diarística: lo inasible del propio yo, lo éxtimo.

\section{4.b) “¿Y por qué, sólo por que escribí, piensan que tengo que seguir escribiendo?"}

Las crónicas que Lispector escribe en el Jornal do Brasil podrían ser pensadas como "performance[s] de lo literario" (Link, 2006), dado que ponen en escena y parodian los protocolos de constitución de la literatura, las figuras del autor y el lector en la

14 "Casi no hay diario íntimo de escritor que no apueste a ese extraño porvenir conjetural. (...) De ahí las dos características básicas que parecen definir la práctica: una disciplina maníaca (nulla dies sine linea), la irresponsabilidad" (Pauls, 1996:3). 
modernidad y en la cultura de los medios masivos de comunicación. Hay tres ejes o instancias alienantes que están en el origen del acting clariceano. En primer término, la cuestión del pago y la profesionalización. Se escribe por necesidad de dinero, lo que implica un primer forzamiento del sujeto en el origen de la escritura. La segunda instancia es la del nombre. Cuando Lispector comienza a escribir las crónicas ya es una escritora reconocida y de cierto éxito. Su nombre se ha vuelto, entonces, una marca registrada. En sus colaboraciones periodísticas previas, Lispector no había estampado la firma o había firmado con pseudónimo. En este momento, sin embargo, el diario debió ver su nombre como un ítem de valor, dado que por primera vez le pide que lo haga. Se trata de una segunda sujeción: ser coherente con su nombre - para lo cual no debe hacer nada, puede ser trivial o brillante: su nombre se impondrá como huella legitimada.

La tercera de las instancias es la del género cronístico y la circulación masiva del periódico, que implica la confrontación con un público amenazante por su heterogeneidad. Desde sus primeras colaboraciones, Lispector se pregunta por el público: "¿qué es lo que más le interesa a la gente?" (2004:16). Y se plantea, ¿con qué llenar ese espacio en blanco que es la columna diaria, ese transcurso en el que se inserta la propia palabra, cuyo principio y fin (la firma) están predeterminados? ¿Cómo evitar reproducir la autoridad hegemónica de la cultura, que implica las tres instancias: profesionalización, nombre de autor y legibilidad? Lispector utiliza una serie de estrategias de rebelión, todas ellas destinadas a restar legitimidad a la propia palabra.

Ante la primera de las instancias, el tema del pago, pone en escena el mero performativo de la escritura. Respetando la convención del título y la firma, hace del resto pura escritura automática. Varias crónicas llevan el título de "Escritura al correr de la máquina". En ellas, se limita a reproducir el gesto, el movimiento físico de escribir, sin posteriores mediaciones intelectuales: "Si ustedes creen que voy a recopiar lo que estoy escribiendo o corregir este texto, se equivocan, va así como está. 
El género de la intimidad

Sólo lo leeré para corregir errores dactilográficos" (2004:262). Corregir sólo los "errores dactilográficos" implica negarse a ser escritor, ser simplemente un copista. Y su inscripción, junto a la frecuente mención de que escribe porque le pagan, es un acto de rebeldía, de burla frente a la idea espiritualizada de escritor que trasciende toda materialidad: "Me pagan para que escriba. Yo escribo, entonces. (...) Pero la vida está muy cara (...) Necesito trabajar mucho para tener las cosas que quiero o necesito" (2004:262). Con respecto a la segunda instancia, la de la autoría, Lispector intenta restarse a sí misma y deconstruir el nombre- deautor: "No soy de dominio público. Y no quiero que me miren. (...) Quiero ser anónima e íntima" (40).

La crónica escribe la irrelevancia, quiebra la idea de estilo, vulgariza el lenguaje volviéndose sentimental, quejosa, exasperadamente íntima. Eso la lleva a la utopía performativa radical, que es la irrupción de la palabra del lector en el texto. El 9 de octubre de 1971, dice

Un lector inventó otra historia sobre el coatí y el hombre, narrativa llena de peripecias, algunas tal vez arbitrarias, algunas profundas. (...) El inventor se dirige a mí como CL. y la firma es una letra única, y para colmo ilegible. Copio íntegramente las aventuras del coatí (...) (2004: 296)

El hecho de transcribir en forma íntegra -sospechamos, sin correcciones - la escritura notablemente críptica del lector, unido a la ininteligibilidad del nombre, pone en escena el quiebre de la función autoral, en una verdadera apología de la mala literatura.

Eso nos conduce a la tercera instancia: la de la forma y su circulación. Los procedimientos disruptivos antes enumerados se hallan fuertemente ligados a una falta de respeto por el género. Clarice recibió varias críticas a su labor como cronista: "Una persona me contó que Rubem Braga dijo que yo sólo era buena en los libros, que no hacía bien las crónicas. ¿Es verdad, Rubem? Rubem, hago lo que puedo" (2004:291). La falta de tema de 
interés público y de reflexión sobre lo social debe leerse como una renuncia ascética. Implica un quiebre de la ilusión de representación: el único emergente en ese territorio yermo es la intimidad, el paisaje interior. Y su tiempo, el puro presente: “...no sé "vestir una idea con palabras". Lo que escribo no se refiere al pasado de un pensamiento, sino que es el pensamiento en tiempo presente..." (2004:226). Esta ascética acarrea un riesgo al sujeto: la exposición de sí. Único tema sobre el que se habla, el yo, contra su voluntad, se delata, revela aquello que no estaba dispuesto a dar, lo que no estaba incluido en el pago: el secreto detrás de la máscara.

$\mathrm{Y}$, también sin darme cuenta, a medida que publicaba para él [se refiere al diario] me iba volviendo demasiado personal, corriendo el riesgo dentro de poco de publicar mi vida pasada y presente, cosa que no quiero (2004:93, la aclaración es mía).

Correr el riesgo máximo, explicitar lo no dicho, es lo que la lleva a la performance autorreferencial:

Hay cosas que jamás diré: ni en libros ni mucho menos en un diario. Y no diré a nadie en el mundo. (...) Agrego: no quiero contarme ni a mí misma ciertas cosas. (...) No, ni piensen que voy a hablar de Dios: es un secreto mío (2004:261).

Acto de afirmación y negación al mismo tiempo, enunciar esa ley implica la traición que constituye su debilidad radical. Mientras lo dejen hablar, el grafómano se delatará en un instante de verdad, y eso es lo que posibilita su alienación. Una vez dicha, su palabra, puro riesgo del lenguaje, podrá ser reutilizada por la institución literaria.

El autor ya no tiene secreto, se ha desnudado. "No quiero decir otra cosa que lo que ustedes quieran oír", dice Lispector, fingiendo inocencia pero revelando, al mismo tiempo, el acto 
El género de la intimidad

demagógico implícito en todo lenguaje que se quiere masivo. El público es la instancia reencantatoria de la escritura clariceana, incluso en el momento de la muerte, del desbarrancarse del yo y de la caída de la máscara. El hecho de que exista alguien que observa, redime el dolor y da sentido al martirio. Con el público como testigo, Lispector se suicida en la escritura, en una performance del desbarrancamiento. Es por eso que la escritura allí es éxtasis, goce puro que se gasta íntegramente en su realización.

\section{5) La escritura femenina como máscara}

Finalizaremos con una reflexión acerca del modo en que la femineidad funciona como máscara o disfraz en la poética de Katherine Mansfield y Clarice Lispector. El tema de la máscara ha sido extensamente abordado por los estudios de género así como por los estudios sobre autobiografía, dado que resulta fundamental para dar cuenta del proceso por el cual las mujeres adquieren voz, $y$ del tipo de representaciones genéricas que utilizan en ese momento crucial en que irrumpen como enunciadoras. En la línea de las reflexiones post-estructuralistas de Paul de Man sobre la autobiografía como enmascaramiento (1991), teóricas como Diane Elam plantean que la autobiografía es "un género imposible" dado que "toda autobiografía produce ficción o figuras en lugar del autoconocimiento que buscan" (Anderson, 2006:120). Si los géneros de la autofiguración enmascaran en lugar de iluminar la identidad, no debe pensarse esta máscara como una imposición puramente externa. Sobre todo en el caso de las mujeres, asumir la máscara puede funcionar como una estrategia paródica de la identidad. Según Joan Riviere, la mascarada encubre -y protegeel deseo de la mujer intelectual de ocupar el lugar de enunciación supuestamente "masculino" mediante la simulación de una femineidad convencional. Judith Butler (2001), por su lado, concibe la máscara como una creativa "producción performativa de la diferencia sexual" y como una "(de)construcción paródica" 
(Butler, 2001:81). Advierte que la máscara femenina no hace más que dar cuenta de la mascarada general, es decir, de la índole artificialmente construida de toda diferencia sexual. Pero, como advierte Toril Moi en su capítulo "Patriarchal reflections" (2002:139), la idea de que la mímica del discurso masculino puede funcionar como un modo de transgredir la lógica patriarcal puede resultar en una performance histérica- mimética que las encierre en un único lenguaje. Asimismo, la propia Butler, en Bodies that matter (1993), contradice la idea de que la constitución de una identidad de género se pueda pensar en términos de enmascaramiento: "La actividad de conferir género no puede ser una expresión humana o un acto, una apropiación voluntaria, y ciertamente no se trata de la cuestión de ponerse una máscara" (1993:7). El género no es asumido voluntariamente como máscara para Butler sino que se trata de una "matriz" anterior, "condición de posibilidad" de todo sujeto.

Sin embargo, para los casos de las escritoras que hemos analizado, es de advertir que, habiendo atravesado por el proceso de subjetivación genérica, las escritoras invierten la operación y crean una parodia o mascarada de esas redes simbólicas que las constituyen. Esos disfraces pueden servir para poner de relevancia los resortes alienantes de toda enunciación y de los roles de género.

En el Diario de Katherine Mansfield puede leerse un rechazo a ocupar el rol de esposa/ mujer/ madre, como amenaza castradora de la libertad. En su Diario (1987:294-295), el marido aparece como ausencia, un fantasma o un pasajero, carente de ataduras. Del mismo modo, vivir juntos - condición socialmente necesaria del matrimonio - es una pura imposibilidad. El yo únicamente expresa su deseo en términos de carencia: lo real "sólo es el sueño de lo que podría ser" (1987:295). En esta escena fantasmática se puede leer entrelíneas un reproche a sí misma por la falta de estabilidad doméstica y por no haber formado una familia (¿Qué es, sino, ese sueño incumplido?) enunciado por la voz fantasmal de la madre. Deberíamos preguntarnos, entonces: 
El género de la intimidad

¿no será contra ese fantasma de lo materno que se constituye la máscara de rebeldía mansfieldeana?

Por otro lado, el concepto de mascarada se muestra ampliamente productivo para pensar la escritura clariceana. En primer lugar, la máscara de la antiintelectual: niega para sí misma el status de escritora, de intelectual o de profesional. Yo no hago literatura, "apenas escribo", dice Lispector en una entrevista de TV. En segundo término, crea la máscara de la mujer misteriosa, metafísica. El yo de la escritora se representa como entidad inaprensible por medio de la razón y, justamente por eso, cercana al gusto del público. En tercer lugar, la máscara de enunciación clariceana encuentra su cristalización más potente en el tópico de la mujer - madre, cotidiana, concernida pura y exclusivamente por cuestiones de belleza, maternidad y vida doméstica:

Soy una mujer que sufre, como todas las personas del mundo, los mismos dolores y los mismos deseos. Yo nunca pretendí asumir una actitud de superintelectual. Yo nunca pretendí asumir ninguna actitud, de hecho. Llevo una vida común y corriente. Crío a mis hijos. Cuido mi casa. Disfruto de ver a mis amigos. El resto es mito (Gotlib, 1995:435).

Claro que el mito-Clarice venía funcionando hace tiempo, como anota su biógrafa, y con éxito. Es esa pose, performance paródica y mascarada de lo femenino, la que nos permite leerla como reivindicación de la potencia reencantatoria de la intimidad.

Si bien la femineidad, como hemos visto, aparece en ambas escritoras como un núcleo paradójico, sería interesante volver a la pregunta por su status liberador. La salida que encuentran las teóricas literarias feministas de la actualidad que estudian la autobiografía, como Linda Anderson (2006), es la de pensar que los escritos confesionales establecen una comunidad de experiencia de mujeres escritoras y lectoras, que comparten los mismos dilemas de constitución de la identidad subjetiva femenina. Esa comunidad de experiencia entre mujeres, cuya 
emergencia hemos analizado en Mansfield $y$ en Lispector, contribuye a restituir valor político a unos escritos muchas veces fragmentarios. Se trata, como dice Anderson, del efecto disruptivo de otras voces, excluidas por razones de raza, género o clase, que emergen en los márgenes del sujeto autónomo unificado, ignoradas por el feminismo hegemónico occidental (2006:27). Demasiado a menudo, ese feminismo ya canónico ha leído a las mujeres del tercer mundo como una identidad en bloque, homogénea, reservando los problemas de constitución del yo para las mujeres occidentales. Leer a dos escritoras como K. Mansfield y C. Lispector, que provienen de ámbitos geográfica, histórica y políticamente desplazados, nos ha permitido formular un cuestionamiento de los géneros literarios canónicos aceptados evitando toda simplificación del sujeto- mujer fuera del ámbito occidental. Tanto Lispector como Mansfield esgrimen complejas concepciones del arte, ponen en acto modos de liberación subjetiva y abren nuevas sendas para la lectora, latinoamericana, anglosajona, e internacional.

\section{Referencias bibliográficas}

ANDERSON, Linda. Autobiography and the feminist subject, En: ROONEY, Ellen. (ed.) The Cambridge Companion to Feminist Literary Theory. Cambridge, Cambridge Univ. Press, 2006, pp.282-321.

BARTHES, Roland. Alain Girard, Le journal intime. En: Variaciones sobre la literatura. México, Paidós, 2003, pp.155- 160.

BURGAN, Mary. Illness, gender and writing. The case of Katherine Mansfield. London, John Hopkins University Press, 1994.

BUTLER, Judith. El género en disputa. El feminismo y la subversión de la identidad. México, Paidós, 2001.

. Bodies that matter: on the discursive limits of "sex". New York, Routledge, 1993.

CARUTH, Cathy. Unclaimed experience: trauma, narrative and history. Baltimore, John Hopkins University Press, 1996. 
El género de la intimidad

DE MAN, Paul. Autobiografía como desfiguración. Suplemento Anthropos, $\mathrm{n}^{\circ} 29$ "La autobiografía y sus problemas teóricos" Barcelona, 1991, pp.113-118.

Deleuze, Gilles y GuATTARI, Felix. ¿Qué es una literatura menor? En: Kafka, por una literatura menor. México, Era, 1978, pp.28-44.

EVANS, Dylan. An introductory dictionary of Lacanian psychoanalysis. New York, Routledge, 1996.

GoRDON, Ian A. Katherine Mansfield. London, Longman, 1954.

GotLIB, Nádia Battella. Clarice - uma vida que se conta. São Paulo, Editora Ática, 1995.

GuÉGUEN, Pierre Gilles. The intimate, the extimate, and psychoanalytic discourse. In: ClEMENS, Justin and GRIGG, Russell. (eds.) Jacques Lacan and the other side of psychoanalysis. Durham and London, Duke University Press, 2006, pp.263-273.

KRISTEVA, Julia. Black sun. Depression and melancholia. New York, Columbia Univ. Press, 1989.

LACAN, Jacques. The ethics of psychoanalysis. 1959-1960. The seminar of Jacques Lacan. Book VII. New York, Norton, 1992.

. The four fundamental Concepts of psychoanalysis. The seminar of Jacques Lacan, Book XI. New York, London, 1981.

LINK, Daniel. Explicación de Clarice. El Interpretador (27), Junio 2006.

LISPECTOR, Clarice. Revelación de un mundo. Buenos Aires, Ed. Adriana Hidalgo, 2004.

LOUREIRO, Angel. (coord.) El gran desafío. Feminismos, autobiografía y posmodernidad. Madrid, Megazul Endymion, 1994.

MANSFIELD, Katherine. Diario. Barcelona, Ediciones Grupo Zeta, 1987.

MILLER, Jacques Allain. Extimité. In: BRACHER, Mark et alii. (eds.) Lacanian Theory of discourse. New York, New York University Press, 1994.

MOLLOY, Sylvia. Identidades Textuales femeninas: estrategias de autofiguración. Mora, $n^{\circ}$ 12, Buenos Aires, FfyL, Dic. 2006, pp.6886.

NATHAN, Roda (ed.) Critical essays on Katherine Mansfield. New York, Macmillan, 1993. 
Alejandra Josiowicz

ORR, Bridget. Reading with the taint of the Pioneer: Katherine Mansfield and settler criticism. En: NATHAN, Roda. (ed.) Critical essays on Katherine Mansfield. New York, Macmillan, 1993, pp.48-60.

Pazos Alonso, Cláudia and Williams, Claire. (eds.) Closer to the wild heart: essays on Clarice Lispector. Oxford, Univ. Of Oxford, 2002.

RIVIERE, Joan. Womanliness as a masquerade. En: Formations of fantasy. London and New York, Ed Routledge, 1986.

RONCADOR, Sonia. A doméstica imaginaria. Brasília, Ed. UNB, 2008.

SMITH, Sidonie. Hacia una poética de la autobiografía de mujeres. Anthropos, $n^{\circ} 29$ - La autobiografía y sus problemas teóricos, Barcelona, Dic. 1991, pp.93-105.

. El sujeto femenino en la escena crítica: la poética, la política y las prácticas autobiográficas. En: LOUREIRO, Angel. (coord.) El gran desafío. Feminismos, autobiografía y posmodernidad. Madrid, Megazul Endymion, 1994, pp.35-67.

ZIZEK, Slavoj. The sublime object of ideology. New York, Verso, 1989. 